\title{
A case of generalized ostraceous psoriasis mimicking dermatitis neglecta*
}

\author{
Bianca A ngelina Macêdo do Nascimento ${ }^{1}$ \\ Carolina Moraes Dias² \\ Clívia Maria Oliveira Carneiro ${ }^{1}$
}

\author{
Alessandra Haber Carvalho ${ }^{1}$ \\ Thaiane Lima Lage ${ }^{2}$ \\ Maraya de Jesus Semblano Bittencourt ${ }^{1}$
}

DOI: http:/ / dx.doi.org/ 10.1590/ abd1806-4841.20153858

\begin{abstract}
Lithium has been implicated in the exacerbation of pre-existing psoriasis, in the induction of psoriasis on previously uninvolved skin of psoriasis patients, and in the triggering of psoriasis for the first time in patients without a personal or family history. Lithium-induced psoriasis (and its resistance to treatment) is one of the major reasons for noncompliance in patients treated with lithium. We describe a male patient who developed generalized ostraceous psoriasis whose clinical appearance mimicked dermatitis neglecta, 10 months after starting therapy with lithium.
\end{abstract}

Keywords: Bipolar disorder; Lithium; Psoriasis

\section{INTRODUCTION}

Despite its widespread use and dermatological adverse events, there are few controlled studies on therapy with lithium. ${ }^{1}$ Psoriasis is its best-known dermatological event and a major reason for treatment discontinuation. We describe the case of a male patient who developed generalized ostraceous psoriasis, whose clinical appearance of the lesions mimicked dermatitis neglecta, 10 months after starting therapy with lithium.

\section{CASE REPORT}

Male patient, 38 years old, reported appearance of painful and itchy "dots" for 2 weeks, initially on the face and with subsequent dissemination and evolution to "dark and thick lesions". He used topical corticosteroids and antihistamines, with no improvement of the condition.

The patient was using risperidone, fluoxetine and carbolithium - the latter introduced for 10 months for treatment of bipolar affective disorder. Dermatological examination revealed erythematous and infiltrated plaques spread over the tegument, associated with dark-brown crusty plaques, located on the scalp, face, chest, back and abdomen (Figure 1). Clinical appearance of the lesions and previous psychiatric history of the patient led to the diagnosis of dermatitis neglecta, however the attempt of manual removal of the plaques with saline solution was performed without success.

Biopsies of lesions on the face and chest were performed. Patient had prescription of antihistamines and oral and topical antibiotics, in addition to request for general laboratory tests as well as HIV, VDRL and HTLV 1 and 2 tests. A natomopathological examination with hematoxylin and eosin stain (HE stain) and biopsy of the face revealed epidermis with confluent parakeratosis, intracorneal aggregates of neutrophils, hypo/ agranulosis, psoriasiform hyperplasia, focal spongiosis and suprapapillary epidermal atrophy. Dermis showed ectatic and tortuous capillary in buds and perivascular lymphocytic inflammatory infiltrate. A bsence of parasites in HE stain and fungi in Grocott stain (Figure 2). Clinicopathological correlation favored the diagnosis of psoriasis and the patient was

\footnotetext{
Received on 14.06.2014.

A pproved by theAdvisory Board and accepted for publication on 19.08.2014.

Study performed at Serviço de Dermatologia da Universidade Federal do Pará (UFPA ) - Belém (PA), Brazil.

Financial Support: None.

Conflict of Interest: None.

Universidade Federal do Pará (UFPA) - Belém (PA) - Brazil.

Private practice - Belém (PA) - Brazil.

(C2015 by A nais Brasileiros de Dermatologia
} 


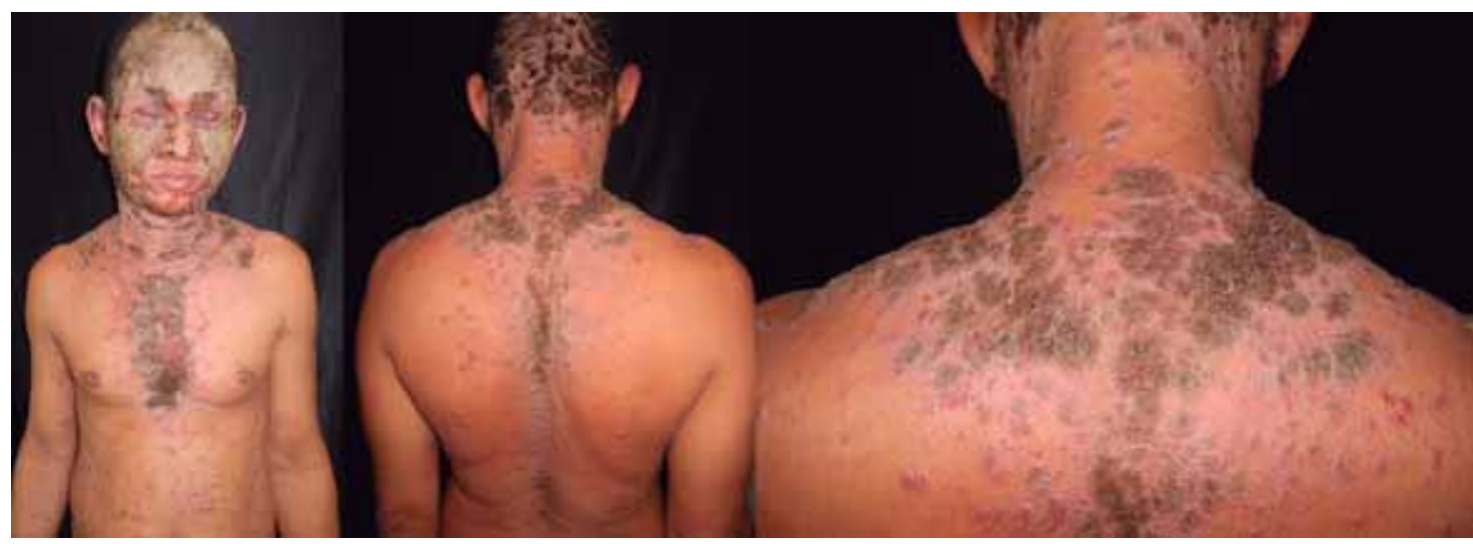

Figure 1:

Clinical appearance of skin lesions, represented by crusty plaques, dark-brown, located on the face, scalp, chest, back and abdomen

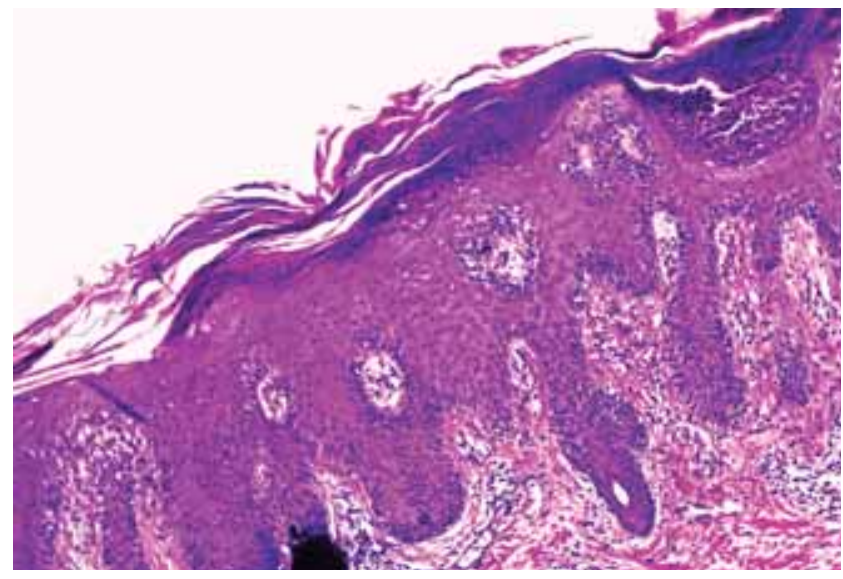

Figure 2: Pathological examination stained with hematoxylin and eosin of the face lesion showing epidermis with confluent parakeratosis, intracorneal aggregates of neutrophils, hypo/ agranulosis, psoriasiform hyperplasia, focal spongiosis and suprapapillary atrophy. The dermis showed ectatic and tortuous capillary in buds and focal perivascular lymphocytic inflammatory infiltrate (HE x40)

instructed to replace carbolithium by methotrexate 15 $\mathrm{mg} /$ week, folic acid $5 \mathrm{mg} /$ week and emollient with urea $10 \%$. One month after this conduct, there was a significant improvement of symptoms, with only residual lesions (Figure 3). The general laboratory tests, HIV, VDRL and HTLV 1 and 2 tests, showed no alterations. At themoment, thepatient presents control of cutaneous clinical condition, receiving a lower dose of methotrexate (10 mg/ week). Psychiatric disorders in being treated with clonazepam, chlorpromazine, risperidone, biperiden and sodium val proate.

\section{DISAUSSION}

Psoriasis is an inflammatory disease with chronic evolution, which affects skin and joints. It occurs by immunological changes genetically based and it can be triggered by numerous environmental

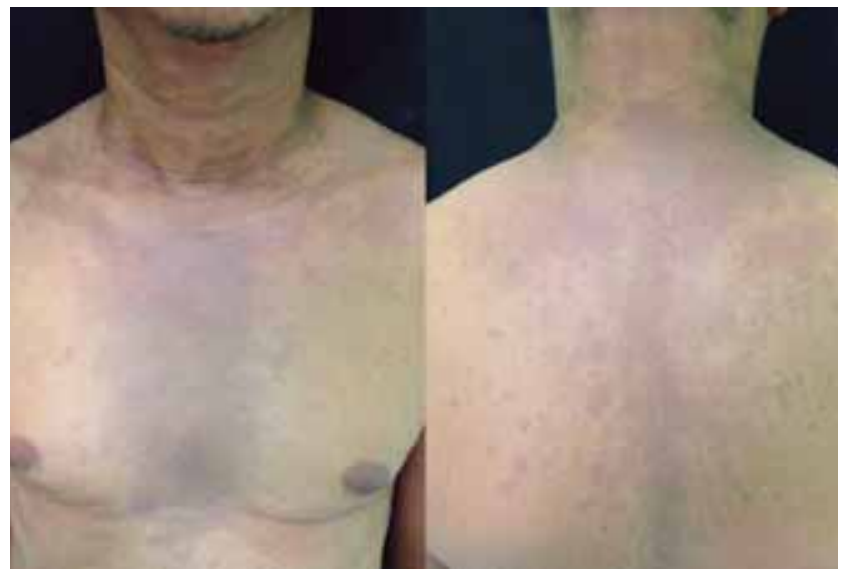

Figure 3: Clinical aspect after one month of suspension of lithium and treatment with methotrexate, with residual dyschromic lesions

stimuli. In terms of clinical condition, the disease can be presented in many ways, receiving special assignments according to the pattern of the lesions or to the anatomical location: plaque psoriasis, guttate, erythrodermic, pustular, nail and arthropathica.

Variations in the morphology of erythematous scaly plaques may be found. Hyperkeratotic lesions can be observed and literature shows several names for these lesions, such as elephantine, rupioid, ostraceous and pseudohorny. 2,3 Authors do not distinguish between these hypertrophic changes and use the terms as synonyms. ${ }^{3}$

The term ostraceous psoriasis was first published by Deutsch as 'atypical psoriasis' in 1898. In this form of psoriasis, the lesions are exuberant horny plaques with a concave inner face, surrounded by a hyperkeratotic ring, and presenting an external surface covered with adherent and thick scales, resembling the shell of oysters. ${ }^{2}$

The dermatitis neglecta was first described in 1995 by Poskitt et al, and it has few cases reported 
in the literature. The disease develops as a result of intentional or unconscious self-neglect of the patient, usually associated with psychiatric disorders. ${ }^{4}$ There is a dermatitis neglecta report mimicking ostraceous psoriasis, but no case of this form of psoriasis mimicking dermatitis neglecta was published. ${ }^{5}$

The hyperkeratotic plaques in dermatitis neglecta are due to the accumulation of sebum, sweat, corneocytes and bacteria, which form compact adherent crusts of dirt, removable with cotton and alcohol or saline solution. ${ }^{4,5}$

The causes of psoriasis are still unknown. It is known that the immune system and genetics has important roles in their genesis. Drug intakemay result in exacerbation of pre-existing psoriasis, induction of psoriatic skin lesions clinically not affected in patients with psoriasis, or precipitation of the disease in people with no family history of psoriasis or in predisposed individuals. 6,7

Mostcommon drugsrelated to this phenomenon are lithium, beta blockers, synthetic antimalarial drugs, nonsteroidal anti-inflammatory drugs, as well as antibiotics, antihypertensives and corticosteroids, among others. ${ }^{7,8}$ Lithium is the basis for the treatment of bipolar disorder. ${ }^{1,6,7}$ Psoriasis induced by lithium is a skin adverse event well documented and one of the main reasons for its suspension, as in this case. The incidence ranges from $1.8 \%$ to $45 \%$ in some studies. ${ }^{1,7}$

The mechanism by which lithium induce or exacerbate psoriasis is not known. It is speculated that its effect is in both cellular and molecular pathway in the modulation of adenylyl cyclase and inositol monophosphatase pathways, glycogen synthase kinase inhibition, which results in keratinocyte proliferation, chemotaxis and phagocytic activity of polymorphonuclear leukocytes, with intercellular edema and vacuolation with the formation of small cavities in the upper dermis. 1,7,9

Refractory period for the development of lesions after initiation of therapy with lithium is variable (mean 12 months), with most of them occurring at therapeutic levels. In the case of our patient, the onset of the lesions occurred 10 months after the introduction of lithium. Reduction or interruption may be considered and the patient can be transferred to another mood stabilizer. ${ }^{1,7}$ Careful monitoring and multidisciplinary approach are useful at the beginning and during the treatment. Although psoriasis induced by lithium is well documented, there are no reports of this condition mimicking dermatitis neglecta, which is so far the first case described in the literature.

\section{REFERENCES}

1. Jafferany M. Lithium and skin: dermatologic manifestations of lithium therapy. Int J Dermatol. 2008;47:1101-11.

2. Bernardi CDV, Schwartz J, Lecompte SM, Trez EG. Ostraceous Psoriasis - Case Report. An Bras Dermatol. 2002;77:207-10.

3. Estrada BD, Azevedo PMC, Tamler C, Aveleira JCR. Comparative dermatology: hyperkeratotic psoriasis. An Bras Dermatol. 2007;82:369-71.

4. Martin LM, Mendes MF, Takaoka LE, Martin MM, Martin BM. Dermatosis neglecta: a report of two cases. An Bras Dermatol. 2010;85:217-20.

5. Park JM, Roh MR, Kwon JE, Lee KY, Yoon TY, Lee MG, et al. A Case of Generalized Dermatitis Neglecta Mimicking Psoriasis Vulgaris. Arch Dermatol. 2010;146:1050-1.

6. Knijff EM, Kupka RW, Ruwhof C, Breunis MN, Prens EP, Nolen WA, et al. Evidence that the immunopathogenic mechanism of lithium-induced psoriasis differs from that of regular psoriasis. Bipolar Disord. 2005;7:388-9.

7. Basavaraj KH, Ashok NM, Rashmi R, Praveen TK. The role ofdrugs in theinductionand/or exacerbation of psoriasis. Int J Dermatol. 2010;49:1351-61.

8. Milavec-Puretić V, Mance M, Ceović R, Lipozenčić J. Drug Induced Psoriasis. Acta Dermatovenerol Croat. 2011;19:39-42.

9. Hampton PJ, Jans R, Flockhart RJ, Parker G, Reynolds NJ. Lithium Regulates Keratinocyte Proliferation Via Glycogen Synthase Kinase 3 and NFAT2 (Nuclear Factor of Activated T Cells 2). J Cell Physiol. 2012;227:1529-37.

\author{
M AILING ADDRESS: \\ $M$ araya de Jesus Semblano Bittencourt \\ 91, Generalíssimo D eodor A venue \\ U marizal \\ 66055-240 Belém - PA. \\ Email: marayabittencourt@hotmail.com
}

How to cite this artide: Nascimento BAM, Carvalho AH, Dias CM, Lage TL, Carneiro CMO, Bittencourt MJS. A case of generalized ostraceous psoriasis mimicking dermatitis neglecta. An Bras Dermatol. 2015;90(3 Suppl 1):S197-9. 